\title{
Primary erythromelalgia
}

INSERM

\section{Source}

INSERM. (1999). Orphanet: an online rare disease and orphan drug data base. Primary erythromelalgia. ORPHA:90026

Primary erythermalgia is characterized by intermittent attacks of red, warm, painful burning extremities. It spontaneously arises during early childhood and adolescence in the absence of any detectable underlying disorder. 